\title{
Un nuevo sistema sanitario: el falso debate entre la sostenibilidad y el negocio
}

\begin{abstract}
A lo largo del último año hemos asistido a la aprobación de diferentes medidas en el ámbito sociosanitario que han cambiado y están cambiando radicalmente tanto el marco de actuación como las condiciones profesionales y laborales de los profesionales de la Salud en España y especialmente en Castilla-La Mancha.
\end{abstract}

Desde la aprobación del Plan de Garantía de los Servicios Sociales básicos de Castilla-La Mancha el 31 de agosto de 2011, cuyo "objetivo irrenunciable" era conciliar la preservación de los servicios sociales básicos y la creación de empleo a través del saneamiento de las cuentas públicas mediante el ahorro de 1.815 millones de euros en el bienio 2011-2012, pasando por la Ley 1/2012, de 21 de febrero, de Medidas Complementarias para la Aplicación de este Plan, hasta la aprobación del Real Decreto-Ley 16/2012, de 20 de abril, de medidas urgentes para garantizar la sostenibilidad del Sistema Nacional de Salud y mejorar la calidad y seguridad de sus prestaciones, resulta vertiginoso observar los profundos cambios que en tan escaso tiempo se están produciendo en nuestro sistema sanitario.

Analizando los preámbulos de ambas disposiciones, no cabe duda sobre lo que para el legislador es el estado de la cuestión: se crea la idea del gasto desmesurado y de la insostenibilidad del Sistema Sanitario tal y como estaba concebido hasta el momento [... la sanidad pública no puede obviar por más tiempo una situación claramente incompatible con su imprescindible sostenibilidad y que, al mismo tiempo, ha acarreado consecuencias gravemente perjudiciales para el empleo y la viabilidad de los sectores empresariales que con él se relacionan]. La solución impuesta ha sido la ya conocida, recortes a todos los niveles del sistema público, desde los recursos humanos hasta en la prestación de servicios. De esta forma venimos asistiendo al despido de profesionales, por ahora centrado fundamentalmente en el sector hospitalario -probablemente el más hipertrofiado en las épocas de bonanza económica- con la consiguiente pérdida de servicios para los ciudadanos, a la restricción de las contrataciones eventuales en Atención Primaria provocando un desorbitado e insoportable incremento de las listas de espera en este nivel asistencial, a las amortizaciones de plazas sin tener en cuenta las condiciones asistenciales del puesto amortizado, a la eliminación de servicios como algunas Unidades de Cuidados Paliativos, que servían de claro apoyo a una Atención Primaria ahogada en burocracia y en una endémica falta de recursos, y a la asfixia de las Unidades Docentes de Medicina de Familia que tan claro ejemplo de eficiencia y buenos resultados han demostrado en los últimos 30 años.
Y sin embargo, ¿realmente hemos gastado más de lo que podíamos permitirnos en la sanidad pública de nuestro país? ¿Realmente es tan insostenible nuestro modelo de atención sociosanitaria? Resulta llamativo que el informe de 2011 del Observatorio para la Sostenibilidad en España ${ }^{1}$, realizara una llamada de atención que sonaba a desesperada: "Desde el año 2009 asistimos a recortes presupuestarios en el sistema sanitario de todas las Comunidades Autónomas. La crisis y el endeudamiento del sistema sanitario se han traducido en recortes en gasto público que tendrá un efecto directo en términos de cohesión social y territorial. La sostenibilidad del sistema sanitario público requiere de más ingresos y no más recortes".

En realidad, más allá del mantra de insostenibilidad del sistema sanitario y del supuesto gasto desmesurado, lo cierto es que en el año 2009 el porcentaje del producto interior bruto (PIB) que España dedicaba al gasto sanitario era del $9,5 \%$, la media exacta de la OCDE, por debajo de países como Francia (11,8\%), Canadá, Dinamarca, Países Bajos, Reino Unido, Estados Unidos (17,4\%) o Alemania $(11,6 \%)$, y por encima de países como Eslovenia, la República Checa, Australia, Israel, Hungría, Polonia, Luxemburgo, México o Turquía.

Por otra parte en el mismo año 2009 (hablamos del inicio de los recortes), el gasto sanitario per cápita en nuestro país era de 3.067 dólares USA ajustados por paridad de poder adquisitivo, por debajo de la media de la OCDE y de todos los países centro y noreuropeos.

En cuanto al gasto público en nuestro país, del $9,5 \%$ del $\mathrm{PIB}$, el $7 \%$ corresponde a gasto público, lo que supone unos $1.700 €$ de gasto público por español y año.

Entonces, si no gastamos ni hemos gastado más que los demás, si más bien nuestro gasto sanitario está por debajo del de países de nuestro entorno, si es precisamente este hecho junto a los resultados sanitarios de nuestra población lo que puso a nuestro sistema como supuestamente "uno de los mejores", ¿de qué estamos hablando realmente?

Hablamos de un evidente y muy trascendente cambio de modelo sanitario en nuestro país. $\mathrm{Y}$ no debe ser interpretado esto como una valoración subjetiva, sino como una evidencia que parte de la propia lectura del RDL 16/2012: "Las medidas que se aplican en el presente real decreto-ley tienen como objetivo fundamental afrontar una reforma estructural del Sistema Nacional de Salud dotándolo de solvencia, viabilidad y reforzando las medidas de cohesión para hacerlo sostenible en el tiempo". Ahora la pregunta es, cómo y hacia dónde. 
No hace falta ir demasiado lejos para averiguarlo. Basta con volver a la lectura de la citada disposición para observar que la condición de Universalidad de la atención queda subrogada a la condición de "asegurado", definiéndose quienes, por ahora, ostentarán esa condición y quiénes no. Queda de esta forma excluido un colectivo altamente sensible como son los inmigrantes no regularizados en los que las consecuencias de la falta de atención y control sanitario están provocando una respuesta de insumisión de los Médicos de Familia encabezada por la semFYC. Por otra parte será definida una nueva Cartera de Servicios dividida en tres modalidades, la cartera de servicios básica, sostenida con financiación pública, la suplementaria y la de servicios accesorios, estas últimas bajo el sistema de copago por el usuario. Parece obvio el camino que esto abre, tal y como dice Sergio Minué2, a los futuros proveedores públicos y fundamentalmente privados de servicios "suplementarios", "accesorios" y, ¿por qué no?, hasta básicos [sic]. Resultan aquí preclaras las declaraciones del señor Echániz, Consejero de Sanidad del Gobierno de Castilla-La Mancha y secretario de Sanidad del Partido Popular al Diario Médico del 23 de mayo de 2012: "La sanidad privada es un complemento imprescindible para la pública, un aliado primordial: es equitativa, ahorradora, eficaz e innovadora". Más allá de la científicamente probada insostenibilidad de esta argumentación resulta llamativa la defensa de la sanidad privada por un servidor de la "cosa pública".

Por tanto, aseguramiento sanitario y privatización, son dos términos que de forma más o menos soterrada subyacen tras las ideas de insostenibilidad y exceso de gasto en una nueva filosofía de Sistema Nacional de Salud muy distinto del que hemos tenido y bastante más cercano al modelo anglosajón del que paradójicamente a duras penas intentan escapar en los Estados Unidos y provoca una fuerte contestación profesional en el Reino Unido. Probablemente no sería necesario recordar que los indicadores de salud españoles hasta ahora eran ostensiblemente mejores que en estos países.

¿Y en Castilla-La Mancha? Nuestra región, avanzada de las reformas y campeona en la defensa y puesta en práctica de las mismas, ha tomado claramente el liderazgo en la toma de decisiones. Decisiones que se han basado en una desmesurada supresión de puestos de trabajo, la eliminación de servicios asistenciales y no asistenciales entre los que están los referidos con anterioridad, una obstinada apuesta por la privatización de la gestión a pesar de las notables dificultades para encontrar al postor correspondiente y una concentración de la gestión en base a Áreas Integradas que allí donde ya se han puesto en marcha han supuesto la desintegración y absorción de las estructuras de la Atención Primaria en las fauces del "monstruo" hospitalario.

Esto ha llevado a que la Atención Primaria como estructura básica, independiente, pilar de la asistencia sanitaria tal y como reconoce la Ley General de Sanidad, haya desaparecido literalmente. Los trabajadores de las Gerencias de Atención Primaria han sido dispersados, los equipos directivos se han visto reducidos a la mínima expresión y los escasos referentes de la Atención Primaria, donde los haya, demuestran una escasísima capacidad decisiva frente a los criterios "hospitalocentristas" instaurados. Los criterios, formas de trabajo y necesidades específicas del primer nivel de atención han sido sobreseídos bajo el pensamiento único hospitalario que entiende la Atención Primaria como un servicio más del hospital. Es, cuando menos, curiosa esta situación si tenemos en cuenta que si algún nivel ha demostrado eficiencia en estas últimas décadas ha sido precisamente la Atención Primaria de Salud.

Y es precisamente la Atención Primaria desde donde se pueden resolver buena parte de los problemas actuales. Los Médicos de Familia y, por extensión, la Atención Primaria, estamos acostumbrados históricamente a trabajar con escasísimos recursos, con muy bajo coste y con los mejores resultados tanto en salud como en satisfacción de los usuarios. Se requiere eficiencia y la Atención Primaria puede aportar mucho en este sentido. Los Médicos de Familia podemos asumir muchos procesos de una forma más barata, más lógica desde un punto de vista científico, más cercana al paciente, a la familia y a la comunidad. Pero necesitamos ser Médicos de Familia, no perder el tiempo en labores administrativas. El Médico de Familia pierde más de un $40 \%$ de su tiempo en facturar "vales de descuento" para las oficinas de farmacia como base de un sistema de prescripción absolutamente irracional, en tareas burocráticas que no han querido hacer otros profesionales o en atender herramientas informáticas desarrolladas para el adecuado control del profesional en vez del control del paciente. Es necesario que los gerentes saquen del cajón las medidas de desburocratización aprobadas con el consenso de las sociedades científicas y el propio SESCAM.

Creemos que es posible mejorar. Todavía hay médicos que resisten las presiones de la administración y de los representantes políticos y siguen trabajando lo mejor posible. Todavía hay médicos dispuestos a aportar lo que creen ser las mejores soluciones, sociedades científicas dispuestas a colaborar en el desarrollo del mejor sistema sanitario posible y así se le hizo saber al Director Gerente del SESCAM en el último Congreso Regional de Atención Primaria. Todavía hay irreductibles galos con ánimo y disposición, pero deberían tener en cuenta la Dirección Gerencia del Servicio de Salud de Castilla-La Mancha y las Sociedades Científicas de Atención Primaria que el Imperio no pudo nunca con la aldea y que éstas últimas tienen la obligación moral de liderar tanto la colaboración como la resistencia si fuera necesario.

\section{BIBLIOGRAFÍA}

1. Sostenibilidad en España 2011 [NIPO: 770-11-264-0]

2. El gerente de mediado, en: http://gerentedemediado.blogspot. com.es/2012/04/la-duda-prudente.html

Enrique González Hidalgo

Especialista en Medicina Familiar y Comunitaria Vicepresidente de la Sociedad Castellano-Manchega de Medicina de Familia y Comunitaria. 